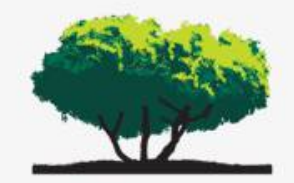

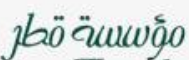
Qatar Foundation

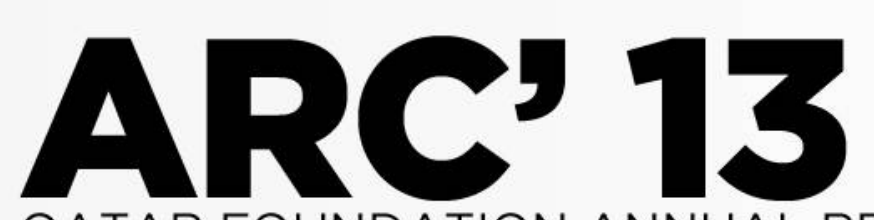

QATAR'S

CROSS-CUTTING

RESEARCH GRAND

CHALLENGES

QATAR FOUNDATION ANNUAL RESEARCH CONFERENCE

Social Sciences and Humanities Pillar

http://dx.doi.org/10.5339/afarf.2013.5SHO-010

\title{
Integrated methodological framework for assessing urban open spaces in Doha from inhabitants' reactions to structured evaluations
}

\author{
Ashraf M. Salama, Fatma Khalfani, Ahood Al-Maimani, Florian Wiedmann
}

Qatar University, Doha, QATAR

Email: asalama@qu.edu.qa*

The current fast track urban growth is an important characteristic of the emerging city of Doha. However, very few studies have addressed several important growth aspects, including the examination of the way in which the inhabitants comprehend and react to their built environment and the resulting spatial experience. The availability of attractive open spaces is an essential feature of a liveable urban environment, for the inhabitants of cities and urban areas. Such importance is sometimes oversimplified when making decisions about land-use or discussing the qualities of the built form. As a city characterized by rapid development, urban open spaces in Doha are scattered around from its peripheries to its centre. Varying in form, function, and scale, some spaces are often located within enclave developments, or within larger urban interventions, while others represent portions of spaces with dense urban districts or open waterfronts. The objective of this paper is to investigate different parameters relevant to the qualities of the most important urban open spaces in the city. It adopts a multi-layered research methodology. First, a photo interview mechanism was implemented where 100 inhabitants reacted to imagery and the spatial qualities of twelve urban open spaces. Second, a walking tour assessment procedure was applied to assess the functional, perceptual and social aspects of these spaces. Results indicate correlations between inhabitants' reactions and assessment outcomes pertaining to positive and demerit qualities. Conclusions are developed to offer recommendations for improving existing spaces while envisioning responsive parameters for the design of future urban open spaces. 